\section{Verankering van de samenwerking tussen beleid, onderzoek en praktijk in de Academische Werkplaatsen Publieke Gezondheid}

\section{Ontwikkeling en toepassing van een monitor}

\author{
D.F. Schokker, ${ }^{1}$ M. Keer, ${ }^{1}$ J.F.E.M. Keijsers, ${ }^{1}$ M.C. Stadlander, ${ }^{1}$ T.G.W.M. Paulussen ${ }^{1}$
}

Het ZonMw-programma Academische Werkplaatsen Publieke Gezondheid (AWPG) is erop gericht duurzame samenwerking tot stand te brengen tussen beleid, onderzoek en praktijk (BOP). TNO ontwikkelde een monitor om informatie te verzamelen over de mate van verankering van deze samenwerking en over mogelijke aangrijpingspunten voor verbetering daarvan.

In de eerste fase van het ZonMw-programma Academische Werkplaatsen Publieke Gezondheid (AWPG) zijn negen AWPG's ontstaan. In deze AWPG's vindt samenwerking plaats op de thema's infectieziekten, epidemiologie, jeugdgezondheidszorg, gezondheidsbevordering en medische milieukunde met als doel om de effectiviteit en doelmatigheid van het publieke gezondheidsdomein waarop zij acteren te verbeteren. De ambitie is om duurzame, gelijkwaardige samenwerking te realiseren en verankeren; dat wil zeggen dat de samenwerking tussen beleid (gemeenten), onderzoek (onderzoeksinstituut) en praktijk (GGD, JGZ) in de AWPG's ook na afloop van het ZonMwprogramma blijft voortbestaan. TNO ontwikkelde in opdracht van ZonMw een monitor met een tweeledig doel: (1) het meten van het proces van verankering van de samenwerking tussen beleid, onderzoek en praktijk (verder afgekort als samenwerking BOP) binnen de AWPG's en (2) het bieden van inzicht in mogelijke aangrijpingspunten voor het verbeteren van die verankering. De monitor is in- middels tweemaal uitgezet, namelijk in juni 2011 en in april 2013. Na een korte beschrijving van de monitor worden de resultaten van deze metingen gepresenteerd.

\section{MONITOR VERANKERING AWPG}

De Monitor Verankering AWPG is gebaseerd op het door Keijsers en Stadlander ${ }^{1}$ beschreven ordeningskader (figuur 1) waarin twee inzichten zijn geïntegreerd: de fasering in het beloop van innovatieprocessen ${ }^{2}$ en de geneste structuur van factoren die een rol spelen in de samenwerking BOP. ${ }^{3}$

Een innovatieproces, in dit geval samenwerking BOP, kent doorgaans een gefaseerd verloop. Er worden op hoofdlijnen drie fasen doorlopen die, bij een positieve beslissingen in voorgaande fasen, uiteindelijk leiden tot de vierde fase: verankering. De beoogde samenwerking

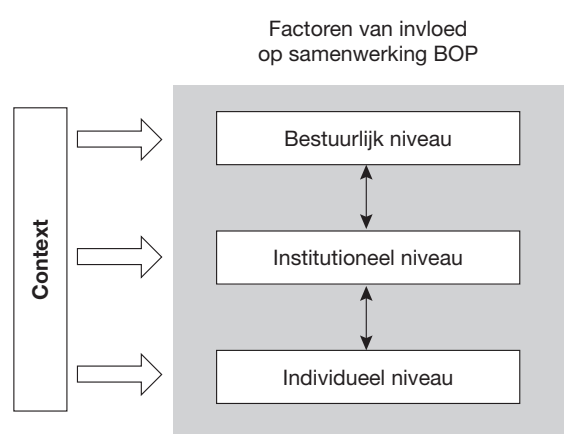

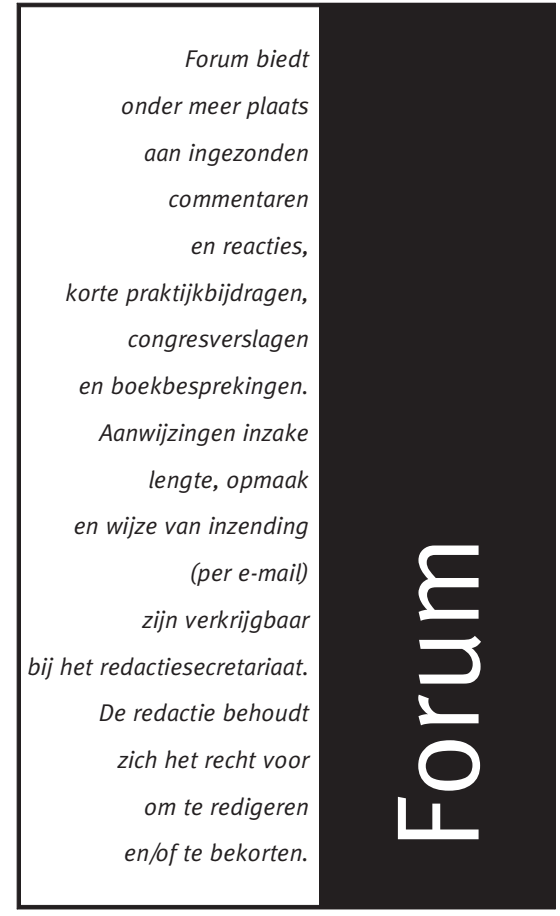

BOP wordt dan niet langer als nieuw ervaren en is een vanzelfsprekendheid geworden in de dagelijkse praktijk. De Monitor Verankering AWPG legt, zoals de naam weergeeft, het accent op deze laatste fase.

Daarnaast wil de monitor inzicht bieden in factoren waarop kan worden gestuurd om deze verankering van de samenwerking BOP te versterken. Deze factoren kunnen op drie invoeringsniveaus worden onderscheiden: bestuurlijk, institutioneel en individueel. Op het bestuurlijke niveau gaat het om factoren gerelateerd aan strategische beleidskeuzes en de allocatie van middelen en menskracht, op institutioneel niveau om de aansturing van werkprocedures binnen de betrokken organisaties, en op individueel niveau staan persoonlijke verwachtingen en ervaringen van professionals centraal.

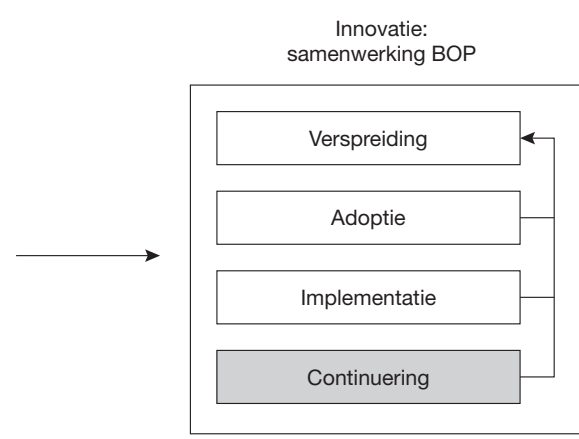




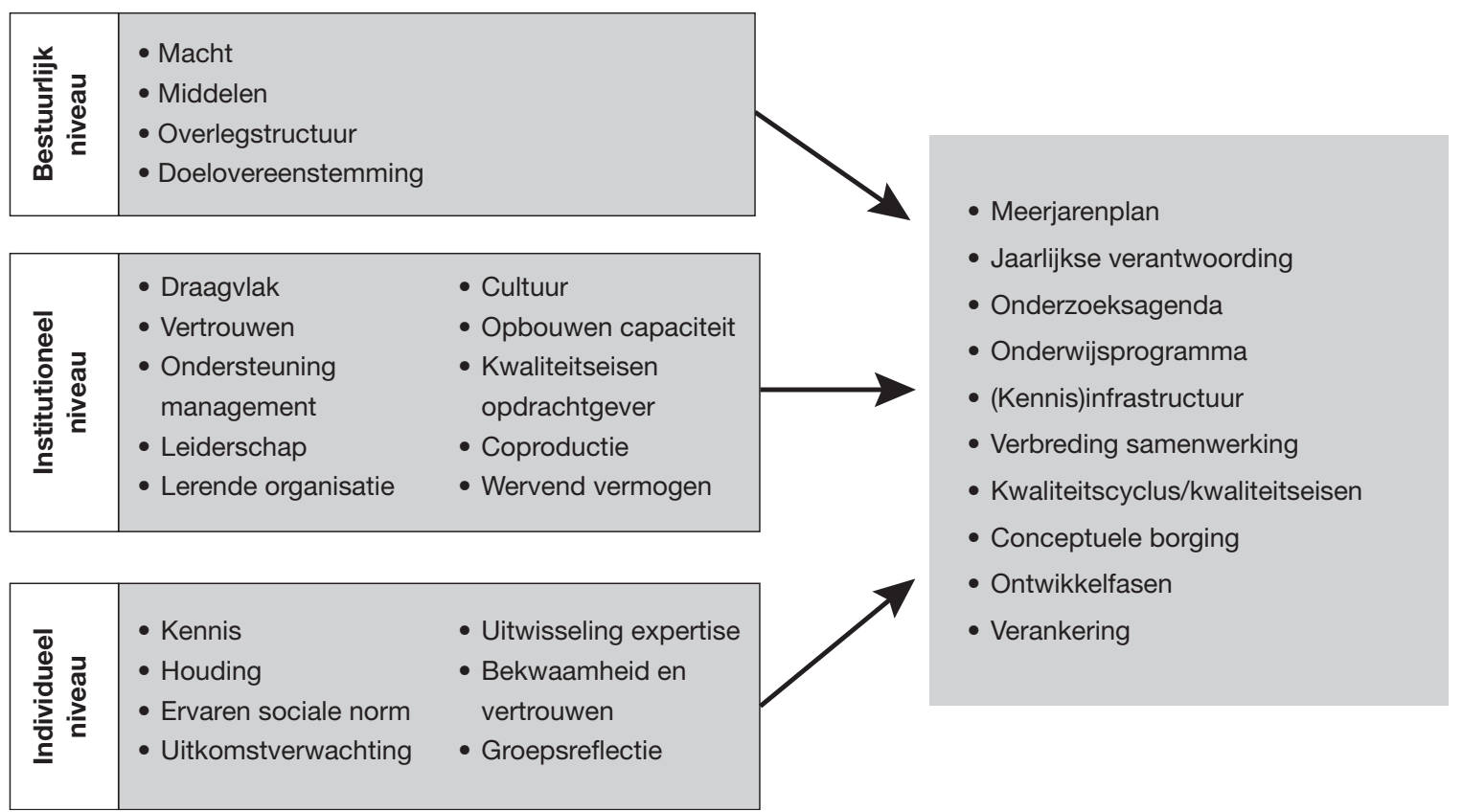

Figuur 2 Model Verankering AWPG: overzicht van factoren en indicatoren voor verankering van de samenwerking BOP in de AWPG's.

Het ordeningskader (figuur 1) is nader uitgewerkt tot het Model Verankering AWPG (figuur 2). Op basis van literatuur ${ }^{3,4-10}$ en gesprekken met onderzoekers is een selectie gemaakt van relevante factoren en in overleg met de coördinatoren en de programmacommissie AWPG van ZonMw zijn tien indicatoren voor de mate van verankering van de samenwerking BOP binnen de AWPG's opgesteld. Vervolgens zijn voor alle factoren en indicatoren vragen opgesteld die door alle betrokkenen bij een AWPG beantwoord kunnen worden, ongeacht of zij bij een beleids-, een onderzoeks- of een praktijkorganisatie werken en of zij werkzaam zijn op strategisch (bestuurders en directieleden), tactisch (middenmanagement) of uitvoerend (professionals) niveau. In overleg met de coördinatoren van de werkplaatsen, de ZonMwProgrammacommissie AWPG en op basis van een pre-test is de Monitor definitief vastgesteld.

\section{Evaluatie}

\section{Dataverzameling en respondenten}

De monitor is in de vorm van een webbased vragenlijst tweemaal uitgezet, in juni 2011 en april 2013. In beide rondes is de coördinatoren van de negen deelnemende AWPG's gevraagd een lijst aan te leveren van alle betrokkenen bij de AWPG. Vervolgens zijn alle betrokkenen (ronde 1: $\mathrm{N}=313$, ronde $2: \mathrm{N}=361$ ), inclusief de coördinatoren, uitgenodigd om de online vragenlijst in te vullen. De resultaten die hier worden gerapporteerd, zijn ontleend aan de respons van de groep die zowel in ronde 1 als ronde 2 deelnam. Die gegevens bieden immers de beste indicatie voor mogelijke veranderingen in de tijd. In de analyses is verder onderscheid gemaakt naar het type organisatie van waaruit respondenten betrokken zijn bij de AWPG. Aanvullend is non-respondenten in ronde 2 gevraagd naar hun voornaamste reden voor hun non-respons.

\section{Factoren en indicatoren}

Om de mate van verankering van een AWPG in een getal te kunnen uitdrukken, is een index samengesteld op basis van de tien indicatoren (zie figuur 2). Deze indicatoren zijn achteraf gedichotomiseerd (o/1) en vervolgens bij elkaar opgeteld tot een index voor de mate van verankering. Deze index kan daarmee een waarde aannemen tussen o (geen verankering) en 10 (maximale verankering).
De factoren van invloed op verankering zijn gemeten met behulp van stellingen gevolgd door een vijf-puntschaal lopend van 'helemaal mee eens' tot 'helemaal mee oneens'. Voor de exacte formulering van de vragen in de monitor verwijzen wij naar het TNO-rapport. ${ }^{11}$

\section{Verdeling van zeggenschap}

Academische werkplaatsen zijn ingesteld met onder meer de centrale gedachte dat gelijkwaardigheid in de relatie tussen de samenwerkingspartners de duurzaamheid van een AWPG zou bevorderen. Daarom is aan de respondenten op een drietal specifieke aspecten gevraagd naar de door hen waargenomen verdeling van 100\% zeggenschap tussen beleids-, onderzoeks- en praktijkorganisaties in de AWPG en de mate waarin zij het eens waren met die verdeling. De drie aspecten waarover zij de zeggenschap verdeelden waren: 1) het gevoerde beleid, 2) de verdeling van middelen en 3) de keuze van projecten. De door respondenten aangegeven verdeling van zeggenschap was zowel in ronde 1 als 2 vergelijkbaar tussen deze drie items (Cronbach's alpha varieerde tussen 0,61 en $0,88)$, zodat een gemiddelde verdeling van zeggenschap over deze drie items kon worden berekend. Datzelfde gold voor de vragen over de mate waarin res- 
Tabel 1 Karakteristieken respondenten ronde 1 en 2 van de Monitor Verankering AWPG.

\begin{tabular}{lc}
\hline Karakteristieken & Totaal N=98 \\
\hline Type organisatie (n, \%) & \\
- Beleidsorganisatie & $9(9 \%)$ \\
- Onderzoeksorganisatie & $25(26 \%)$ \\
- Praktijkorganisatie & $64(65 \%)$ \\
Functieniveau (n, \%) & \\
- Strategisch & $15(15 \%)$ \\
- Tactisch & $39(40 \%)$ \\
- Operationeel & $44(45 \%)$ \\
AWPG (n, \% van totaal) & \\
- Agora & $8(8 \%)$ \\
- AMPHI & $19(19 \%)$ \\
- JGZ Noord-Holland & $7(7 \%)$ \\
- Sarphati & $10(10 \%)$ \\
- Milieu \& Gezondheid & $11(11 \%)$ \\
- Noordelijk Zuid-Holland & $17(17 \%)$ \\
- Brabant & $13(13 \%)$ \\
- CEPHIR & $6(6 \%)$ \\
- Limburg & $7(7 \%)$ \\
Aantal jaar betrokken bij AWPG [in ronde 2] & \\
- Gemiddeld (sd) & $4,7(2,4)$ \\
\hline
\end{tabular}

pondenten het eens of oneens waren met de verdeling (Cronbach's alpha=0,62).

\section{RESULTATEN}

\section{Respons}

Van de respondenten uit ronde 1 waren er 133 die ook in ronde 2 nog betrokken waren bij hun AWPG. Van hen hebben er 98 de vragenlijst in beide rondes ingevuld (respons: 74\%). Tabel 1 geeft een overzicht van het type organisatie van waaruit respondenten bij de AWPG betrokken zijn. Per AWPG varieerde het aantal respondenten tussen de 6 en 19 en de respons tussen $50 \%$ en $87 \%$. Respondenten waren ten tijde van ronde 2 gemiddeld 4,7 jaar betrokken bij hun AWPG. De meeste respondenten waren betrokken vanuit een praktijkorganisatie (65\%). Een kwart was werkzaam bij een onderzoeksorganisatie (26\%) en 9\% bij een beleidsorganisatie. In aanvullend onderzoek naar de non-respons werd door 21 respondenten uit ronde 1 aangegeven wat hun voornaamste reden was om niet deel te nemen aan ronde 2 . In zeven gevallen was dit 'geen tijd', drie personen gaven aan dat zij de vragen lastig vonden om in te vullen en nog eens drie personen waren afwezig in de periode van het onderzoek wegens vakantie of verlof. Overige redenen werden door slechts één of twee personen genoemd.

\section{Mate van verankering}

De gemiddelde scores op de index voor de mate van verankering staan weergegeven in Tabel 2. Deze gemiddelde score is significant toegenomen van 5,2 in ronde 1 naar 5,9 in ronde $2(p<0,001)$. Deze stijging was zichtbaar bij alle AWPG's en bij respondenten uit alle drie de typen organisaties. Respondenten uit onderzoeks- en praktijkorganisaties hadden in beide rondes een hogere score op de index dan respondenten werkzaam bij beleidsorganisaties.

Nagegaan is welke factoren in ronde 1 een significante verklaring boden voor de variantie in de scores op de index. Hiertoe zijn allereerst met de data van ronde $1(N=154)$ univariate correlaties bepaald tussen de factoren en de score op de index. De factoren die significant met de index correleerden, zijn vervolgens opgenomen in een multivariaat regressie- model, met de score op de index als uitkomstmaat. De factoren werden 'forward' aan het model aangeboden (opgenomen indien $p<0,05$; verwijderd indien $p>0,10)$. Dit leverde uiteindelijk een regressiemodel op met vijf factoren die elk een uniek deel van de variantie in de index-score wisten te binden: doelovereenstemming $(B=0,461)$, cultuur $(B=0,747)$, lerende organisatie $(B=0,956)$, kennis $(B=0,789)$ en uitwisseling van expertise $(B=0,803)$. De verklaarde variantie door deze vijf factoren bedroeg $46 \%\left(R^{2}=0,463\right)$.

Met de data van beide rondes werd gekeken naar de invloed van de factoren op de verandering van de score op de index. Hiertoe werd een regressieanalyse gedaan met de score op de index in ronde 2 als afhankelijk variabele, de score op de index in ronde 1 [vast] met één van de factoren [univariaat] als onafhankelijke variabelen. Hier bleek de factor wervend vermogen een significante bijdrage te leveren $(p=0,030)$.

\section{Verdeling van zeggenschap}

Respondenten verdeelden $100 \%$ van de door hen waargenomen zeggenschap als volgt over de drie typen organisaties: beleidsorganisaties hadden in ronde 1 volgens de respondenten gemiddeld $21 \%$ zeggenschap over het beleid, de verdeling van middelen en de keuze voor projecten in de AWPG; voor onderzoeksorganisaties lag dit op $43 \%$ en voor praktijkorganisaties op $36 \%$. In ronde 2 verdeelden de respondenten deze zeggenschap als volgt: beleidsorganisaties $20 \%$, onderzoeksorganisaties $41 \%$ en praktijkorganisaties $39 \%$. Slechts $38 \%$ (ronde 1 ) en $43 \%$ (ronde 2 ) van de respondenten was het met de door hen aangegeven verdeling eens.

Respondenten die in ronde 2 meer tevreden waren met de verdeling van zeggenschap dan in ronde 1 , namen in ronde 2 minder zeggenschap voor de onderzoeksorganisaties waar: respondenten waren meer tevreden geworden

Tabel 2 Scores op de index van verankering (gemiddelden en SDs).

\begin{tabular}{|c|c|c|c|c|c|}
\hline & Ronde 1 & $\begin{array}{l}\text { p-waarden } \\
\text { (ANOVA) }\end{array}$ & Ronde 2 & $\begin{array}{l}\text { p-waarden } \\
\text { (ANOVA) }\end{array}$ & $\begin{array}{l}\text { p-waarden verschillen ronde } 1 \text { en } 2 \\
\text { (gepaarde t-test) }\end{array}$ \\
\hline TOTAAL $(\mathrm{N}=98)$ & $5,2(2,4)$ & & $5,9(2,5)$ & & 0,001 \\
\hline Type organisatie & & $<0,001$ & & $<0,001$ & \\
\hline - Onderzoek $(n=25)$ & $5,9(2,6)$ & & $6,8(2,6)$ & & 0,018 \\
\hline - Praktijk $(n=64)$ & $5,3(2,2)$ & & $5,9(2,3)$ & & 0,027 \\
\hline
\end{tabular}


met de verdeling naarmate de door hen aangegeven verdeling gelijkwaardiger was geworden.

\section{CONCLUSIE}

Dit artikel beschrijft de Monitor Verankering AWPG. Deze monitor biedt inzicht in het verankeringsproces van de samenwerking tussen beleid, onderzoek en praktijk in de AWPG's. Bij alle AWPG's blijkt de mate van verankering van de samenwerking BOP in april 2013 toegenomen in vergelijking met de resultaten van de meting in juni 2011. Er lijkt sprake te zijn van een redelijk gelijkwaardige samenwerking tussen onderzoeks- en praktijkorganisaties, maar beleidsorganisaties lijken hierbij achter te blijven. Dit komt tot uiting in respectievelijk de score op de index voor de mate van verankering en de gerapporteerde verdeling van zeggenschap (en tevredenheid daarover). Voor het verankeren van een gelijkwaardige samenwerking BOP in de AWPG's, verdient de zeggenschap van en samenwerking met beleid dus aandacht.

Kijkend naar de index van verankering, dan blijken zes factoren een significante invloed te hebben op mate van verankering: gepercipieerde doelovereenstemming (bestuurlijk niveau), cultuur, wervend vermogen en aspecten van de lerende organisatie (institutioneel niveau) en kennis en uitwisseling expertise (individueel niveau). De factoren die in de Monitor Verankering AWPG zijn geadresseerd, en dan met name bovengenoemde factoren, bieden samen met andere evaluatiebronnen en ervaringen van betrokkenen bij de AWPG's goede aanknopingspunten voor gerichte sturing van de verankering van de samenwerking BOP binnen de AWPG's.

\section{ABSTRACT}

Continuation of collaboration between policy, research and practice in the Academic Collaborative Centres for Public Health: development and application of a monitor.

The program Academic Collaborative Centres (ACCs) for Public Health is aimed at creating sustainable collaboration between policy, research and practice in order to improve the quality of public health. The institutions collaborating within an ACC are the community health services, a university department, and one or more municipalities. TNO developed an instrument for monitoring the process of continuation of this collaboration and identifying its determinants. Such information can be used for guiding the collaboration within the ACCs. This article presents the development of the ACC Monitor as well as the results of its application. The monitor has been applied in June 2011 and April 2013. The results show an improvement in the level of sustainability of collaboration in the Academic Collaborative Centres, but the involvement of policy organizations lags behind. Also, the determinants that were significantly associated with the degree of sustainability of the collaboration between policy, research and practice are stated.

Keywords: Academic Collaborative Centres, sustainable collaboration between policy, research and practice, indicators

\section{LITERATUUR}

1. Keijsers JFEM, Stadlander MC. Achtergrondnotitie Criteria voor verankering AWPG. Den Haag: ZonMw, 2009.

2. Paulussen Th, Pin R, Mesters, I. Interventiedisseminatie en -implementatie. In: Brug J, Asseman P van, Lechner L (eds). Gezondheidsvoorlichting en gedragsver- andering, een planmatige aanpak. Assen: Van Gorcum/Open Universiteit, 2012.

3. Jansen M. Mind the Gap: Collaboration between practice, policy and research in local public health. Proefschrift. Maastricht: Universiteit Maastricht, 2007.

4. Wehrens $R$, Bekker M, van Egmond $S$, Putters $K$, Bal R. De Academische Werkplaats als grensorganisatie - De coördinatie van onderzoek, praktijk en beleid in de Academische Werkplaatsen Publieke Gezondheid. Tijdschr Gezondheidswet 2008;86:288-95.

5. Wehrens R, Bekker M, Bal R. Academische Werkplaatsen in ontwikkeling: ontwikkelstadia, knelpunten en opbrengsten van vijf jaar samenwerking. In: Jansen M, Burhenne K (red). Hoge hakken, lange tenen. Successen van en valkuilen voor de Academische Werkplaatsen Publieke Gezondheid in Nederland. GGD Zuid Limburg, 2011.

6. Mootz M. Positionpaper Academische Werkplaatsen. Den Haag: ZonMw, 2010.

7. Harting J, Stronks K. Integratie van praktijk, beleid en wetenschap: verbreed de blik, verruim het denken. Tijdschr Gezondheidswet 2010;88:232-3.

8. Wagemakers A, Koelen MA, Lezwijn J, Vaandrager $L$. Coordinated action checklist: a tool for partnerships to facilitate and evaluate community health promotion. Global Health Prom 2010;17:17-28.

9. Jansen M, Burhenne K (red). Hoge hakken, lange tenen. Successen van en valkuilen voor de Academische Werkplaatsen Publieke Gezondheid in Nederland. Geleen: GGD Zuid Limburg, 2011.

10. Pre Post 42. Werkplaats Veranderd. Den Haag: ZonMw, 2011.

11. Schokker DF, Keer M, Keijsers JFEM, Paulussen TGWM. Eindrapport monitor verankering AWPG: Samenwerking tussen beleid, onderzoek en praktijk in de Academische Werkplaatsen Publieke Gezondheid. Leiden: TNO, 2013.

CORRESPONDENTIEADRES Dieuwke Schokker, TNO, Schipholweg 77-89, 2316 ZL Leiden, e-mail: dieuwke.schokker@tno.nl 